\title{
Narrativa periodística en la convergencia de medios
}

\author{
Andrés BARRIOS RUBIO \\ Universidad de Bogotá Jorge Tadeo Lozano (Colombia) \\ andres.barrios@utadeo.edu.co
}

Recibido: 1 de febrero de 2015

Aceptado: 15 de septiembre de 2015

\begin{abstract}
Resumen
El de hoy es un entorno en el que todos los días los medios sufren cambios estructurales y funcionales que los obligan a replantear su accionar y reinventar sus usos y esquemas de comunicación, de ahí la importancia de esta investigación mixta, cuantitativa y cualitativa, que recurrió a seguimiento en redes sociales y análisis de contenidos; detectando el cómo los medios responden al estar inmersos en un mundo en el que se pasó de una cultura de imprenta a una cultura de la pantalla donde surgen nuevas prácticas sociales que crean dispositivos a la medida de cada uno, elementos en los que conjugan el texto, el audio y el video configurando nuevos medios en los que se generan otras formas de interacción, y se replantea el quehacer profesional del Comunicador Social - Periodista.
\end{abstract}

Palabras clave: Transmedia, Comunicación, Periodismo, Redes, TIC.

\section{Journalistic narrative media convergence}

\begin{abstract}
The today is an environment in which every day the media undergo structural and functional changes that force them to rethink their actions and reinvent their practices and communication schemes, hence the importance of this mixed quantitative and qualitative research, which turned to monitor social networks and content analysis; detecting how the media respond to being immersed in a world where it went from a print culture to a culture of the screen where new social practices that create devices to measure each, elements that combine arise text the audio and video setting new media in which other forms of interaction are generated and professional work rethinks Social Communicator - Journalist.
\end{abstract}

Keywords: Transmedia, Communication, Journalism, Networks, TIC.

\section{Referencia normalizada}

BARRIOS RUBIO, Andrés (2016): "Narrativa periodística en la convergencia de medios". Estudios sobre el Mensaje Periodístico. Vol. 22, Núm. 1 (enero-junio), págs.: 163-176. Madrid, Ediciones Complutense.

Sumario: 1. Introducción: el periodismo transmedia, un campo de acción en la convergencia de medios. 2. Metodología. 3. Resultados. 4. Discusión. 5. Aproximación a un esquema de comunicación del periodismo transmedia. 6. Reflexiones finales. 7. Referencias bibliográficas.

\section{Introducción: el periodismo transmedia, un campo de acción en la conver- gencia de medios}

Estamos en un entorno en el que todos los días los medios sufren cambios estructurales y funcionales que los obligan a replantear su accionar y a reinventar sus usos y esquemas; se puede decir que nos encontramos en un mundo en el que se pasó de una cultura de imprenta a una cultura de la pantalla donde surgen nuevas prácticas sociales que crean dispositivos a la medida de cada uno, elementos en los que conjugan el texto, el audio y el video configurando nuevos medios en los que se generan nuevas formas de interacción. Lo antes planteado implica un replanteamiento en la labor profesional de los comunicadores sociales - periodistas, en busca de responder a las necesidades del mercado, pues se requieren hoy periodistas "transmedia" que estén 
capacitados para llegar a un público conformado por la generación@, jóvenes con nuevas coordenadas espacio-temporales que delimitan el espacio virtual y gracias a la tecnología tienen al mundo en la palma de su mano.

A comienzo del siglo XXI el centro de estudio sobre las TIC estaba en los fenómenos de la multimedia y la interactividad, pero con la velocidad de las transformaciones y el impacto que ello implica eso quedó atrás y hoy todos fijan la mirada en la convergencia de medios y lo que Jenkins (2003) llama, la narrativa transmedia ${ }^{1}$. Un eje de diálogo que centra su accionar en la elaboración de productos comunicativos que requieren: el uso de más de un medio como soporte a las necesidades del tema o mensaje; "los medios de comunicación son anfitriones, facilitan espacios compartidos dentro de los cuales el público consume, compone, sube, descarga, resuelve, crea, participa, cocrea una experiencia mediática" (Scolari, 2013: 157).

Desde su comienzo se vio y entendió el término multimedia como la unión de tres formatos: texto, audio y vídeo; lo cual no pierde validez, sin embargo hoy se debe profundizar más en ello y llevarlo al ámbito empresarial donde se habla de la combinación e integración de tres medios (prensa, radio y televisión) en uno, con las implicaciones y consecuencias que ello conlleva (Salaverria, 2003). En tal sentido, el periodista debe dominar cada medio y ser competente en el quehacer profesional en dicho panorama que exige el surgimiento de nuevos lenguajes y el establecimiento de una relación más cercana y de complicidad entre el medio de comunicación y sus usuarios.

Los mass media se encuentran en una etapa de replanteamiento y adaptación en la que se reconfiguran y reinventan para competir en igualdad de condiciones con lo que se conoce como nuevos medios o medios del entorno digital. Se hace referencia a un panorama en el que las estrategias de la empresa mediática apuntan a un nuevo esquema de elaboración, distribución y consumo de contenidos. Un proceso de comunicación en el que prima la conversación entre un sinnúmero de actores ávidos de un espacio en el cual dar a conocer su punto de vista, al tiempo que intercambian información con su red, de amigos o seguidores, sin importar el tiempo, la distancia y el espacio.

Es un ecosistema mediático que pide estar preparado para llevar a la audiencia una historia a través de diversas plataformas ${ }^{2}$ (medio convencional, página Web, YouTube, Twitter, Facebook, entre otros), de modo que se brinden múltiples miradas sobre ese hecho que se quiere llevar a los usuarios (Molano, 2012). Una convergencia que al decir de Jenkins es el "flujo de contenido a través de múltiples plataformas mediáticas, la cooperación entre múltiples industrias mediáticas y el comportamiento migratorio de las audiencias mediáticas, dispuestas a ir casi a cualquier parte en busca del tipo deseado de experiencias de entretenimiento" (2008: 14).

1 Narrativa Transmedia (Transmedia Storytelling): Término acuñado por Henry Jenkins en 2003 para hacer referencia a aquellos tipos de relato que responden a dos características: 1. Se propaga a través de varios medios y plataformas, y 2. El público o prosumidor (productor + consumidor) participa de manera activa en la diseminación del mensaje (Scolari, 2013).

2 Se entiende por plataforma, el espacio físico o digital que sirve como base para el funcionamiento de las propuestas comunicativas en la Web. 
Se hace evidente que, en los medios de comunicación, hoy cobra relevancia aquella estrategia publicitaria del media mix en donde se produce todo un proyecto de comunicación en el que cada medio desde sus argumentos narrativos genera un mensaje particular que es reforzado por el otro desde sus particularidades para llevar al sujeto a la acción planificada. Es un proceso que Deuze describe "en términos de una mayor cooperación y colaboración entre redacciones de medios anteriormente separados y otras partes de la empresa periodística" (2004: 140). Un mundo narrativo que se complementa con el del otro para conformar ese gran entorno y contexto en el cual se desenvuelve una sociedad en particular y el usuario es el protagonista principal recontextualizando los argumentos narrativos desde su experiencia personal.

La labor de construcción social de la realidad no está hoy solo en manos de los medios sino en un entorno colaborativo en el que participan todos los actores sociales en conjunto con los mass media y las plataformas tecnológicas que surgen todos los días. En este sentido, los mecanismos de mediación se convierten en dispositivos que potencian, re-dimensionan, bloquean, permean, las relaciones constitutivas de los grupos en su interior y en el contacto con otros; lo que abre a nivel social campos de estudio, sociológico y cultural (Jenkins, 2006), en el que se debate el papel constitutivo de las mediaciones en la relación entre los sujetos, el entorno, los medios y el contexto.

Los medios de comunicación hoy han cambiado sus esquemas productivos, aquello que hacían de manera aislada en el pasado, a través del medio convencional, hoy se integra, en el entorno digital, para ofrecer contenidos multimedia en los que el receptor es protagonista (Lawson-Borders, 2006). Se habla de un protagonismo, no solo por las diversas alternativas que se le presentan al usuario para llegar a la propuesta comunicativa del medio, transmedialidad, bajo un esquema de interactividad e hipervínculos desde las redes sociales, sino, porque es productor de información, al tiempo que ayuda a expandir el mensaje con sus redes de amistad particulares.

La narrativa transmedia debe estar diseñada de tal modo que no importe por dónde comience el usuario su recorrido, pues el desarrollo de la historia lo irá llevando por cada uno de los caminos y será él quien decida dónde quiere profundizar y bajo cuál óptica realizará su reconstrucción de la realidad. Es acá donde el hilo narrativo tiene una clave fundamental para la comprensión del mensaje, pues se tendrá una visión total del mundo cuando el sujeto ha tenido acceso a las diferentes plataformas, soportes y canales en los cuales se diseminó la historia que se pretende llevar al público (Rivera, 2012).

Se habla de un juego de dominio propuesto desde los medios en donde se le da ciertas libertades al usuario para reconstruir los hechos y generar nuevas narrativas desde sus redes sociales y micro blogs, al tiempo que se aprovecha el conocimiento del receptor para proponer alternativas, respuestas y soluciones acordes a su contexto. Es lo que Deuze (2008) llama periodismo ciudadano, espacio donde el usuario sin saber y dominar las potencialidades de cada medio, ni formular estrategias de comunicación, estructura mensajes de manera efectiva a través del dialogo social.

La evolución tecnológica, y el poder que cada día toman las redes sociales, replantean el modelo de negocio de los mass media, de modo que se bajan los costos y 
se maximiza la producción a través de propuestas comunicativas para los diversos dispositivos (Quinn, 2005). Con su presencia en la red, los medios de comunicación y sus periodistas se vieron obligados a evolucionar en la manera de crear, usar y distribuir contenido (Jaramillo, 2011), y buscar alternativas para innovar, de modo que involucran a la audiencia y la vuelven protagonista del esquema comunicativo.

Los medios atraviesan por un proceso de convergencia empresarial, tecnológico, profesional y comunicativo en el que a través del ensayo y error se reinventan y reacomodan, a los retos y necesidades que plantea un sistema en el que a través de la confluencia de tecnologías se replantean los esquemas de producción (Salaverría, García \& Masip, 2008). La audiencia ha evolucionado y hoy comienzan a recibir nuevos actores, conocidos ellos como los "nativos digitales" o "generación@”" los cuales están definidos por su forma de relacionarse con el entorno, y entre sí, a través de las múltiples pantallas que les proporcionan las TIC.

Se está al frente de un mundo en el que es necesario comprender los elementos de la composición y la percepción visual, manejar los elementos y códigos que utiliza el lenguaje audiovisual para expresar significados coherentes y comprensibles que den sentido al relato que se ofrece; el éxito de la narración, propuesta a través de múltiples plataformas, está directamente ligado a la experiencia del usuario y su capacidad de desplegar nuevas experiencias de ello.

Ahora, más que antes, toma relevancia aquella postura de Marshall McLuhan (1988) de "el medio es el mensaje". La labor del periodista en este entorno transmedia requiere definir cuál es el centro del relato, $\mathrm{y}$ al mismo tiempo poseer un adecuado conocimiento de los diversos medios de comunicación y el cómo codificar la propuesta comunicativa en cada uno de ellos, de modo que se brinden herramientas de construcción narrativa que vinculan y enlazan las historias proporcionadas a través de otras plataformas.

Es necesario saber llevar relatos, interpretar adecuadamente ese contexto socio-cultural particular que permite al público comprender la complejidad del mundo que vive, al tiempo que haciendo uso de una narrativa transmedia se aglutina el mayor número de espectadores frente a una historia, apasionándolos por aquello que se les comunica (Molano, 2012). Se habla de un proceso en el que cada uno busca su espacio en el entorno digital, en el cual no solo se es conocido, sino recordado, como una alternativa de uso, producción y consumo de información a través de múltiples plataformas, respetando los lenguajes y esquemas de comunicación propios de cada medio.

La presencia de los mass media en el entorno digital implica no solo una convergencia de medios sino una narrativa conjunta (transmedia), que respalda unas políticas bajo las cuales se defienden unos valores, ideas y criterios con los cuales se concibe y presenta el mundo. Un panorama que impone un arduo trabajo a los medios no solo en la identificación de su audiencia, los problemas que aquejan a esos receptores y la solución a esos problemas, sino al replanteamiento de unos objetivos, estrategias y tácticas para llegar con sus productos comunicativos a las masas; elementos que arrojan unos resultados medibles y propician unos ajustes y cambios acordes a las necesidades de esa red de usuarios que busca satisfacer sus necesidades con el medio de comunicación. 
Atrás quedó la etapa en la que el objetivo estaba en adaptarse al mercado, hoy el foco de atención está en encontrar esa red de consumidores con intereses comunes que son atraídos por una propuesta comunicativa a la cual ellos contribuyen con sus experiencias e historias, aquello que los usuarios consideran verdaderamente interesante y pueden llegar a compartir con emoción y entusiasmo.

Los medios y sus periodistas comienzan a comprender la necesidad de los usuarios que buscan nuevos conceptos y propuestas comunicativas en los mass media, oportunidades de ser protagonistas de conversaciones con aquellos que antes estaban alejados en la producción mediática y esos otros que hacen parte de la red de usuarios que encuentran elementos de interés comunes con el medio de comunicación.

\section{Metodología}

La investigación que ahora se referencia se centró en la influencia de las redes sociales en la creación de contenidos y en el establecimiento de la agenda radial colombiana, enmarcándose en un espectro más amplio del fenómeno de la globalización de la cultura, de los consumos informativos y culturales y de las transformaciones sociales mediadas y mediatizadas por las nuevas tecnologías. Con ello se busca identificar la incidencia del nuevo entorno mediático en el accionar de la labor periodística, así como en la creación de contenidos, con el fin de avanzar en la comprensión de las transformaciones culturales y sociales derivadas de la introducción de las TIC en la sociedad de hoy.

Este texto, es producto de una investigación que se desarrolló mediante una metodología mixta, cuantitativa y cualitativa, lo que permitió equiparar los resultados numéricos con el análisis de los post y twittes de las redes sociales, de 6 emisoras de Bogotá - Colombia, (Silverman, 2000). Un criterio fundamental para la selección de este universo fue la aceptación de las emisoras, los 6 primeros puestos en el ranking de audiencia de emisoras a nivel nacional, en el ECAR ${ }^{3} 3$-2013; y las características que aporta la capital de los colombianos (diversidad sociocultural, étnica, racial, de credos e ideologías).

A través de fichas de análisis se pretendió establecer una etnografía virtual que permitiera dar cuenta de la relación de los mass media con sus oyentes en el entorno virtual y la respuesta de los usuarios a la acción comunicativa de la emisora. Se concibe las plataformas modernas (Facebook y Twitter) como un punto de encuentro en el que se reunen medios de comunicación y cibernautas para conformar una red de amistad, complicidad y sociabilidad (Ardèvol et al, 2003: 73).

El proceso de análisis de los mensajes y su contenido inició con valoraciones diagnósticas en función de las nuevas necesidades del medio, de los receptores y de las empresas relacionadas con el sector de las comunicaciones. Se incluyeron evaluaciones sumativas que sirvieron para integrarlas al estudio global, lo que permitió un examen de valor en el momento de su discusión (Urchaga, 2009).

${ }^{3}$ Estudio Continuo de Audiencia Radial, realizado por el Centro Nacional de Consultoría en 3 olas de 4 meses cada una al año. 


\section{Resultados}

Las emisoras que fueron objeto de seguimiento en sus cuentas de Twitter y Facebook se determinaron acorde al número de oyentes como se muestra en la Tabla 1. De ellas 4 son musicales y 2 de contenido hablado, 4 pertenecen a la Cadena Caracol de Colombia (Caracol Radio, Tropicana, Oxígeno y W Radio) 1 a la Radio Cadena Nacional (La Mega) y 1 a la Organización Radial Olímpica (Olímpica Estéreo).

Tabla 1. Emisoras objeto de estudio y sus oyentes.

Fuente: Elaboración propia con los resultados del ECAR 3-2013

\begin{tabular}{|l|l|l|l|l|l|l|}
\hline Emisora & $\begin{array}{l}\text { Olímpica } \\
\text { Estéreo }\end{array}$ & $\begin{array}{l}\text { Caracol } \\
\text { Radio }\end{array}$ & La Mega & Tropicana & Oxígeno & $\begin{array}{l}\text { W Radio } \\
\text { Colombia }\end{array}$ \\
\hline \# Oyentes & 2.980 .800 & 2.180 .900 & 2.097 .900 & 1.988 .800 & 1.462 .000 & 1.367 .200 \\
\hline
\end{tabular}

Para el seguimiento de las cuentas de Twitter se determinó tomar como referencia los últimos 3200 twittes, de las emisoras que se encuentran en análisis, los cuales fueron descargados haciendo uso de la palaforma Twitonomy, http://www.twitonomy.com. Los resultados son sintetizados y expresados en la Tabla 2:

Tabla 2. Estadísticas en Twitter.

Fuente: Elaboración propia con los datos de Twitonomy

\begin{tabular}{|l|c|c|c|c|c|c|}
\hline \multicolumn{1}{|c|}{ Medio / Característica } & $\begin{array}{c}\text { Olímpica } \\
\text { Estéreo }\end{array}$ & $\begin{array}{c}\text { Caracol } \\
\text { Radio }\end{array}$ & La Mega & Tropicana & Oxígeno & $\begin{array}{c}\text { W Radio } \\
\text { Colombia }\end{array}$ \\
\hline Promedio twittes por día & 107.854 & 1.725 .658 & 1.185 .616 & 84.639 & 290.191 & 1.693 .107 \\
\hline RT realizados por la cuenta & 5 & 94 & 33 & 32 & 15 & 128 \\
\hline Usuarios mencionados & 1.115 & 350 & 3.185 & 2.642 & 3.442 & 298 \\
\hline Respuestas brindadas & 70 & 1 & 39 & 26 & 90 & 1 \\
\hline Hipervínculos insertados & 2.746 & 2.854 & 2.018 & 2.520 & 2.594 & 3.175 \\
\hline Hashtags & 1.431 & 888 & 1.839 & 3.238 & 1.735 & 1.058 \\
\hline Twittes que recibieron RT & 1.891 & 2.714 & 2.303 & 1.335 & 2.447 & 3.098 \\
\hline $\begin{array}{l}\text { RT que recibieron los mensajes } \\
\text { emitidos por el medio }\end{array}$ & 6.107 & 24.007 & 8.442 & 2.317 & 11.157 & 23.985 \\
\hline $\begin{array}{l}\text { Twittes que recibieron } \\
\text { "Favorito" }\end{array}$ & 1.766 & 2.691 & 3.051 & 2.411 & 2.960 & 3.016 \\
\hline $\begin{array}{l}\text { "Favorito" que recibieron los } \\
\text { mensajes emitidos por el medio }\end{array}$ & 4.103 & 17.519 & 20.851 & 6.040 & 24.310 & 20.761 \\
\hline
\end{tabular}

Analizando la actividad de los medios en las redes sociales se puede apreciar un alto número de movimientos en las redes sociales $(60,69 \%)$ dedicados a hacer referencia a las noticias que se emiten en la programación habitual "Falleció joven de 19 años herido, al parecer, por un policía en Cali bit.ly/10cqa1A", haciendo una clara autopromoción de los contenidos (13,12\%) "Viva con Caracol Radio el Minuto a Minuto: Colombia vs Nicaragua bit.ly/ZY8UOm” y dejando muy relegados los comentarios dirigidos (11,91\%) “El principal objetivo de una reforma a la Ley 100 es simplificar el sistema de salud? Ministro@agaviriau \#WRadio” y las interacciones con los seguidores (4,99\%) "RT \#FrasesdelCarnaval "No, no me mate déjeme goza máteme si quieres después del carnaval”.@EmisorAtlantico”.

Frente a los programas se aprecia una fuerte preocupación por referenciar las cuentas personales de los periodistas $(72.48 \%)$ "Al aire la segunda hora del \#TropiShow 
con@tatasolarte@JuniorPardo@Memoorozcol,por la@Tropibogota”y la autopromoción del medio, programas y fuentes (93,29\%) "Diego Rueda@diegonoticia en Madrid con Falcao García@FALCAO”, al tiempo que se referencian los temas tratados al aire.

Se contató que los principales periodistas de los medios más influyentes del país tienen un $38.20 \%$ de interacciones diarias en las que generan algún tipo de contacto con sus seguidores “@marioScantor Si, he estado y son maravillosos y baratos. Gracias!', mientras que se genera una gran actividad frente a la información y direccionamiento a los portales del medio, con comentarios dirigidos, hipervínculos a los periodistas, a los medios, al programa y a las mismas fuentes "Acabo de hablar con @pardodaniel Me parece que es muy válido oírlo mañana en el programa e invitaré a alguiende@kyenyke a que nos acompañe”.

Frente a Facebook se revisaron los portales del medio y se extraen los datos estadísticos de la herramienta Likealyzer, http://likealyzer.com, los cuales se muestran en la Tabla 3.

Tabla 3. Estadísticas Facebook. Fuente: Elaboración propia con los datos de Likealyzer

\begin{tabular}{|l|c|c|c|c|c|c|}
\hline Medio / Característica & $\begin{array}{l}\text { Olímpica } \\
\text { Estéreo }\end{array}$ & $\begin{array}{l}\text { Caracol } \\
\text { Radio }\end{array}$ & La Mega & Tropicana & Oxígeno & $\begin{array}{l}\text { W Radio } \\
\text { Colombia }\end{array}$ \\
\hline Seguidores & 39.336 & 268.410 & 1.050 .459 & 44.389 & 151.796 & 21.170 \\
\hline Publicaciones por día & 11 & 115 & 7 & 7 & 20 & 19 \\
\hline $\begin{array}{l}\text { Me Gusta, comentarios y } \\
\text { acciones por post }\end{array}$ & 124 & 61 & 29 & 8 & 152 & 17 \\
\hline
\end{tabular}

Los contenidos de los medios están marcados por el concepto tradicional de lo que es noticia, temas de interés general que afectan a un gran número de personas política, económica, social, y culturalmente. Poco a poco la radio asimilia el entorno digital y desarrolla la capacidad de escribir para internet, hacer videografías, fotografías, emplamar audio, video e información bajo la diferencia de lenguaje, forma y contenido que ello implica. Se trata de enriquecer el producto comunicativo con creatividad, permitir a los usuarios oír y vivir en el mundo que está en la calle.

Queda en evidencia al comparar las cifras de los medios en las dos redes sociales más populares que la apuesta digital de las emisoras colombiana se encuentra en Twitter, espacio en el que la radio potencia su propuesta sonora complementandola con notas, videos y sonidos hipervinculados en la página Web del medio. Una labor de marketing sobre el consumo de sus contenidos y los del grupo mediático al que pertenece.

\section{Discusión}

Con la incorporación de las TIC y todas sus plataformas en el quehacer de los sujetos se cambió completamente la conceptualización de las profesiones, el mundo se abrió en todo sentido y se ubicó al alcance de todos. En el caso del periodismo hoy se compite no solo con los otros medios de comunicación sino con los miles de reporteros volantes gratuitos que circulan por las redes sociales, personas que brindan tendencias al registrar todo aquello que ven, pero que deben ser asumidos con responsabilidad por parte de los medios al autenticar la veracidad de aquello que llega desde los diversos 
rincones del mundo para profundizar y contextualizar en el relato que se ofrece al usuario.

El ser humano hoy está rodeado de un sinnúmero de blogs, micro-blogs, redes y micro-redes, espacios en los que se entablan conversaciones públicas y privadas que dan lugar a pequeñas comunidades, con intereses comunes, las cuales se protegen bajo todo tipo de estrategias y de las cuales es muy difícil salir. Se habla de un mundo totalmente globalizado en el que no hay ninguna gran barrera como para no interactuar con cualquier persona, comunidad o empresa en los diversos rincones del mundo, un espacio en el que muchos ya superan el obstáculo que implica la diferencia de idiomas al generar un espacio con un código común, el del entorno digital.

El entorno de redes en el que actúan los medios y los profesionales de la comunicación ha generado una nueva escala de valores en la relación con los usuarios, un espacio en donde prima la colaboración, la sindicalización de la información, el diálogo y la respuesta a las necesidades de uno y otro. Bajo ese cibermundo, los usuarios rompen brechas y son más cercanos a sus periodistas, las redes sociales y las TIC permiten que el oyente entre un poco en la vida, la cotidianidad, los defectos, las pasiones, los gustos, los sentires y muchas cosas más de quienes producen y realizan los productos que encuentra en las distintas plataformas analógicas y digitales.

Las redes sociales, y las TIC en general, han impactado en el mundo porque son igualadoras sociales que responden a una necesidad innata del ser humano, esas ansias de comunicación con el otro, de saber más del otro o de eso que está pasando a la distancia, respuestas que se encuentran rápidamente en el mundo tecnológico en el cual todos ingresan y dejan su visión particular frente a uno y otro tema. Es decir, dejan su testimonio y contribuyen a la narrativa testimonial de un mundo particular.

Los recursos digitales se han convertido en la herramienta de comunicación más instantánea que existe en el mundo, ello obliga que el profesional de la comunicación se prepare para afrontar dicho entorno y explotar el material que ellas le proporcionan. Se trata de aplicar las concepciones tradicionales del periodismo, al tiempo que se esfuerza por concebir un material de manera diferente: ofrecer un producto más ameno, más agradable, que recurre a una serie de estrategias para contextualizar y complementar lo que en él se dice.

El periodismo ha modificado su accionar, la forma de llegar a la información, la forma de producir los contenidos, el cómo se llega a la gente, pero en el fondo sigue siendo el mismo; es decir, una profesión subjetiva en la que la objetividad es un ideal de la academia y que en la realidad no pasa de ser equilibrado, o no equilibrado, bajo la subjetividad que tiene el tema en quien origina el mensaje. Es un trabajo que bajo un lenguaje generalista busca satisfacer a todos los actores y sujetos del acto comunicatio.

La alta dosis tecnológica que hoy acompaña, no solo a los seres humanos sino, a los mass media diversificó la relación entre los medios de comunicación tradicionales y los medios del entorno digital, de modo que el usuario llega a los contenidos no solamente por los aparatos o terminales tradicionales, sino que comprende una nueva narrativa que implica la confluencia de herramientas y plataformas con sus lenguajes, ventajas y limitaciones. Un espacio de convergencia en el que cada medio se rein- 
venta y potencia esa característica diferencial que tiene sobre el otro, es decir, se pasa por una etapa en la que el negocio no se acaba sino que se transforma y se adapta al entorno digital de las audiencias.

Una narrativa transmedia en el periodismo, la integración de una historia a través de diversos medios y plataformas, fragmentada de manera intencional, distribuida acorde a las características de cada medio. Es decir, la profundidad y capacidad de análisis de un medio escrito, la inmediatez, generación de sensaciones y portabilidad de la radio, la capacidad de visualización y recreación de la televisión, y la globalización, interacción y accesibilidad de los medios digitales. Es saber conjugar de manera estratégica el mundo en línea con el convencional.

Si se hace un análisis minucioso de los mensajes que circulan en la red, se puede apreciar que la influencia de las redes sociales y los mass media es mutua; la agenda de la red social, en el campo informativo, se basa en lo que está pasando en la prensa, la radio y la televisión, en lo que se discute en los medios de comunicación. Por su lado, la agenda de los medios, en el campo de los temas triviales, graciosos, de injusticia, entre otros, está marcada por lo que ocurre en las redes sociales y adquiere relevancia por las tendencias y el número de usuarios que se manifiestan en el mensaje.

Los productos comunicativos hoy tienen mayor vigencia y todos pueden llegar a él en el momento que consideren necesario, antes existían parrillas de programación $\mathrm{y}$ espacios determinados para el consumo de un programa radial, una serie o la propuesta que tenía el medio de comunicación, pero las necesidades del momento, la rapidez de los acontecimientos y las necesidades de información llevaron a que gracias a la tecnología se abrieran nuevos espacios de consumo en el que tanto medios como comunicadores explotan su deseo de recordación.

\section{Aproximación a un esquema de comunicación del periodismo transmedia}

La creación y proliferación de plataformas y medios de comunicación en el entorno digital, permite que un enorme número de personas reciban el mismo mensaje, en cadena o en tiempos diferenciales, pero al mismo tiempo lo recontextualicen y propongan nuevas narrativas frente a los hechos. Es un espacio en el que tanto emisor como receptor tienen un papel protagónico, en el que suplen sus necesidades informativas y hacen propuestas comunicativas desde diversas ópticas, esquemas y plataformas haciendo uso de las herramientas e instrumentos que están disponibles en el entorno convencional y digital.

Un panorama en el que no existe un solo texto informativo, el público toma los datos de varios medios, los comparte y de manera colaborativa reconstruye el universo narrativo que da pie a la noción de realidad. El profesional de la comunicación transmedia, en el desarrollo de su labor profesional, debe tener claro que la historia se debe complementar en cada medio y por ello debe estructurar un eje narrativo para cada plataforma o mass media de tal forma que cada una de las partes queda interconectada de algún modo, respetando el principio de la narrativa transmedia, en la que no cabe la linealidad.

En el entorno digital no todos los mensajes son interpretados de la misma manera, ni generan el mismo grado de interés o importancia, es un proceso de interpretación 
que está determinado por factores como la cultura, la clase social y la pertenencia a un grupo específico, lo cual es la base de los Estudios Culturales, centro de atención de la investigación en comunicación en Latinoamérica durante los últimos años, donde hay una preocupación latente por conocer a ese receptor de los medios; un ser social que mantiene una relación conflictiva con el concepto de Estado, la asimilación de la tecnología y la resistencia de lo popular frente a lo moderno.

El panorama de la comunicación se transformó totalmente, el profesional de los medios trabaja bajo un contexto cambiante de la profesión, al tiempo que se desempeña bajo las tensiones estado-medios-sociedad propias de la región latinoamericana. Se hace referencia a un entorno en el que surje la necesidad de detectar un modelo de comunicación bajo el cual operar en lo que se denomina periodismo transmedia.

Partiendo de los tradicionales modelos de comunicación de Shannon y Lasswell, el autor de este artículo propone una aproximación al esquema de comunicación que se presenta en el periodismo transmedia, Anexo 1, Gráfico 1. No pretender ser la última palabra frente al tema, pero sí abrir la discusión que determine un campo de estudio profundo que defina el proceso comunicativo que se da en el nuevo ámbito profesional del periodismo, en el que confluyen medios, actores y una serie de características que redefinen el campo de acción.

Para hablar de un esquema de comunicación del periodismo transmedia se debe tener en cuenta a los actores que hacen parte del proceso (personas, medios, plataformas, tecnología, contexto, ambiente) bajo los cuales se concibe, produce, circula y recibe el mensaje, para a su vez generar nuevas narrativas que impacten no solo al emisor inicial sino a las redes de receptores y amigos.

El profesional de la comunicación se vincula a los conglomerados de medios desde donde ejerce su actuación profesional empleando los cánones tradicionales del periodismo. Como primer emisor desarrolla un producto comunicativo, que dejan en evidencian sus competencias lingüísticas, semióticas, argumentativas, sociales y tecnológicas. Ese mensaje es codificado acorde al lenguaje propio de cada medio que servirá de canal para llevar la propuesta visual, sonora o escrita al usuario, que puede ser un individuo aislado o integrante de una red de seguidores.

El receptor del mensaje, que responde a unas necesidades comunicativas, de reconocimiento y amistad, se convierte en un segundo emisor al momento de retomar el producto comunicativo: asimilarlo, reconfigurar su narrativa y recontextualizarlo bajo sus competencias lingüísticas, semióticas, argumentativas, sociales y tecnológicas. Una vez se concibe el mensaje, con las modificaciones incorporadas por el usuario, se codifica para ser distribuido por las plataformas digitales. Es decir, se da circulación a una nueva propuesta comunicativa que impacta al periodista (emisor 1) y a otros usuarios (emisor 2) de modo que se continúa con el flujo de la información bajo el modelo que ahora se propone.

El modelo de periodismo transmedia evidencia momentos y componentes que tienen su propia complejidad desde la perspectiva que cada medio y plataforma tiene su propio lenguaje, códigos de comunicación, componentes técnicos que confluyen con un público determinado que entra a hacer parte del proceso narrativo superando las interferencias que puede significar los elementos distractores, las competencias tecno- 
lógicas de los actores y la situación física bajo la cual se realiza el proceso comunicativo. Un sistema relacional de factores que emergen bajo unas dimensiones políticas, económicas, sociales, éticas, estéticas, culturales e ideológicas.

\section{Reflexiones finales}

Inmersos en el campo tecnológico tanto los medios de comunicación como los usuarios comprendieron que el panorama lleva a un entorno colaborativo en el que convergen las distintas alternativas de comunicación para generar una narrativa transmedia en la cual se potencia la imaginación y la creatividad de cada uno de los participantes. Poco a poco los mass media se desarrollan digitalmente y los profesionales de la comunicación se culturizan, tecnológicamente hablando, lo que permite que el proceso de producción de contenidos sea mucho más fácil y el público, "nativo digital", percibe un mejor producto con líneas de acción para cada generación.

Hoy existe una clara apuesta de los mass media por vincular al mercado mediático a la "generación@”, ese público que aprende e interactúa a través de las pantallas y se le debe llegar a través de un proceso casi que imperceptible en el que se incorporan nuevas claves de acción e interacción entre unos y otros, al tiempo que se construye la tradicional confianza entre el medio y los usuarios.

Los medios se convierten en plataformas que asumen el costo de creación de información dando respuesta a la inmediatez del mundo de hoy, al tiempo que se construyen narrativas que permiten establecer un contexto, una profundización y un análisis sobre los hechos. Publicar una noticia, un post o un twitte, requiere de mayor esfuerzo creativo y originalidad, tener un elemento diferenciador que llame la atención del usuario, pues los receptores tienen a su disposición un sinnúmero de propuestas similares con las cuales interactuar y satisfacer sus necesidades de información y consumo.

Las redes sociales y el entorno digital permiten que los medios y sus periodistas estén más cercanos al receptor, puedan dar cuenta de lo que quieren y de lo que opinan, se convierten en una guía frente a un tema o acción determinada. Todo está dado en el panorama para generar una propuesta de calidad, la clave está en sorprender con contenidos y narrativas a través de diferentes plataformas, en las que el comunicador se adapta a los nuevos modelos y esquemas con los cuales llegar a la gente.

Los medios se convierten en plataformas que permiten a los usuarios no solo llegar a la información sino hacer uso de ella, para generar nuevas propuestas, al tiempo que las comparte. Algo similar a lo que sucede en las redes como Facebook, Twitter, Whatsapp e incluso Linkedin. Los medios y plataformas del entorno digital fueron invadidos por los mass media que encontraron en ellos un escenario fundamental e ideal para llamar la atención, al tiempo que difunden sus contenidos.

Se está al frente de un nuevo panorama mediático en el que se abren espacios de colaboración a los usuarios, pero al mismo tiempo se generan vínculos de seguimiento, mayores a los existentes tradicionalmente. Por ahora la presencia en la red más que rentable, es un trabajo a largo plazo para responder a las necesidades de la "generación@”, que busca el consumo de información y entretenimiento en múltiples espacios y pantallas de manera simultánea. Se está al frente de un proceso de la sociedad de consumo que lleva implícito una escala de valores que transforma el comporta- 
miento de los usuarios bajo un esquema de conexión y colaboración en el que prima la información, la atención y los espacios de participación.

Cada día surgen herramientas digitales que impactan el quehacer profesional y simplifican los procesos, pero alrededor de la tecnología siempre estará la parte humana, ese elemento que es vital en la propuesta que se lleva al usuario, y va de la mano con el proceso creativo que nutre ese contenido de los medios. No cabe duda que los formatos están cambiando para suplir esos espacios de soledad que acompañan al ser humano, esa necesidad de aceptación y de pertenecer a un grupo (red) determinado.

Se está al frente de un entorno comunicativo en el que los códigos cambian y se generan nuevas estrategias para llegar a la audiencia con temas y lenguajes comunes a los de ellos. En el entorno transmedia se conjuga el papel de emisor y receptor, todos en un momento determinado se encuentran en una u otra posición, enriqueciendo el discurso con la participación conjunta y las particularidades de cada uno.

Los jóvenes, y con ellos la audiencia mayor, que hacen parte de la industria digital, a través de las diferentes plataformas y medios digitales complementan la visión fragmentada que tenían de la sociedad. Surge la necesidad de establecer los parámetros bajo los cuales se actúa en un entorno, personal y profesional, en línea, en el que las industrias creativas llevaron a la sociedad a interactuar a través de pantallas y desarrollar el tacto. Un mundo cada vez más segmentado en redes específicas, comunidades pequeñas, en las que se generan nuevas dinámicas de comunicación; narrativas de construcción colectiva de la realidad que requieren de legitimación en su propiedad y uso.

\section{Referencias bibliográficas}

ARDEVOL, Elisenda et al. (2003): "Virtualized Ethnography: participant observation and semi-structured interviews online". Athenea digital, núm. 3, pp. 72-92.

CENTRO NACIONAL DE CONSULTORÍA (2013): Estudio general de medios 32013.

DEUZE, Mark (2008): "The professional identity of journalists in the context of convergence culture". Observatorio, vol. 4, núm. 2, pp. 103-117. En: http://www.obs.obercom.pt/index.php/obs/article/view Article/216

DEUZE, Mark (2004): "What is multimedia journalism?. Journalism studies, vol. 5, núm. 2, pp. 139-152. http://www.inormaworld.com/smpp/content $\sim$ content $=\mathrm{a} 713704861 \sim \mathrm{db}=\mathrm{all}$

JARAMILLO, Ana María (2011): Redes sociales para todos, su negocio en la Web 2.0. Bogotá, Ediciones B.

JENKINS, Henry (2008): Convergence culture. La cultura de la convergencia de los medios de comunicación. Barcelona, Paidós.

JENKINS, Henry (2006): Convergence Culture. Where Old and New Media Collide. New York, New York University Press.

JENKINS, Henry (2003): “Transmedia Storytelling. Technology Review”. En: http://www.technologyreview.com/news/401760/transmedia-storytelling/ 
LAWSON-BORDERS, Gracie (2006): Media organizations and convergence: case studies of media convergence pioneers. New Jersey, Lawrence Erlbaum.

McLUHAN, Marshall (1988): El medio es el masaje. Barcelona, Paidós.

MOLANO, Adriana (2012): "Transmedia la nueva narración". Colombia Digital, en: http:/www.colombiadigital.net/cultura-digital/producciones-destacadas/item/3708transmedia-la-nueva-narración.html

QUINN, Stephen (2005): “Convergence's Fundamental Question". Journalism Studies, vol. 6, I, pp. 29-38

RIVERA, Diego (2012): “¿Qué es transmedia y storytelling?”. Medios Sociales, en: http://www.mediossociales.es/transmedia-y-storytelling/

SALAVERRÍA, Ramón (2003): “Convergencia de Medios”. Revista Latinoamericana de Comunicación Chasqui, núm. 81, pp. 32-39. En: http://scholar.google.com/citations?view_op=view_citation\&hl=es\&user=tkMu2WEAAAAJ\&citation_for_vi ew=tkMu2WEAAAAJ $:$ r0BpntZqJG4C

SALAVERRÍA, Ramón; GARCÍA, José Alberto; \& MASIP, Pere (2008): “Media Convergence as a Research Concept: A Proposal for Its Theoretical and Operational Definition". 2nd European Communication Conference ECREA. Barcelona.

SCOLARI, Carlos (2013): Narrativas Transmedia. Madrid, Editorial Grupo Planeta.

SILVERMAN, David (2000): Doing Qualitative Research. A Practical Handbook. Thousand Oaks, Sage.

URCHAGA, José David (2009): “Análisis de Contenido”. En REYES, Román: Diccionario Crítico de Ciencias Sociales, vol. I, pp. 147-151. Madrid-México, Universidad Complutense \& Plaza-Valdés.

Andrés Barrios Rubio es comunicador social, periodista y profesor universitario. Especialista en Edición Digital y Multimedia. Director Emisora Óyeme UJTL Coordinador Programa de Tecnología en Producción Radial. Profesor Asociado II en el Programa de Comunicación Social - Periodismo de la Facultad de Ciencias Sociales de la Universidad de Bogotá Jorge Tadeo Lozano. Bogotá - Colombia. Es Magister en Administración de Empresas con Especialidad en Dirección de Proyectos. Doctorando en Contenidos de Comunicación en la Era Digital (Universitat Autònoma de Barcelona) 


\section{Anexo}

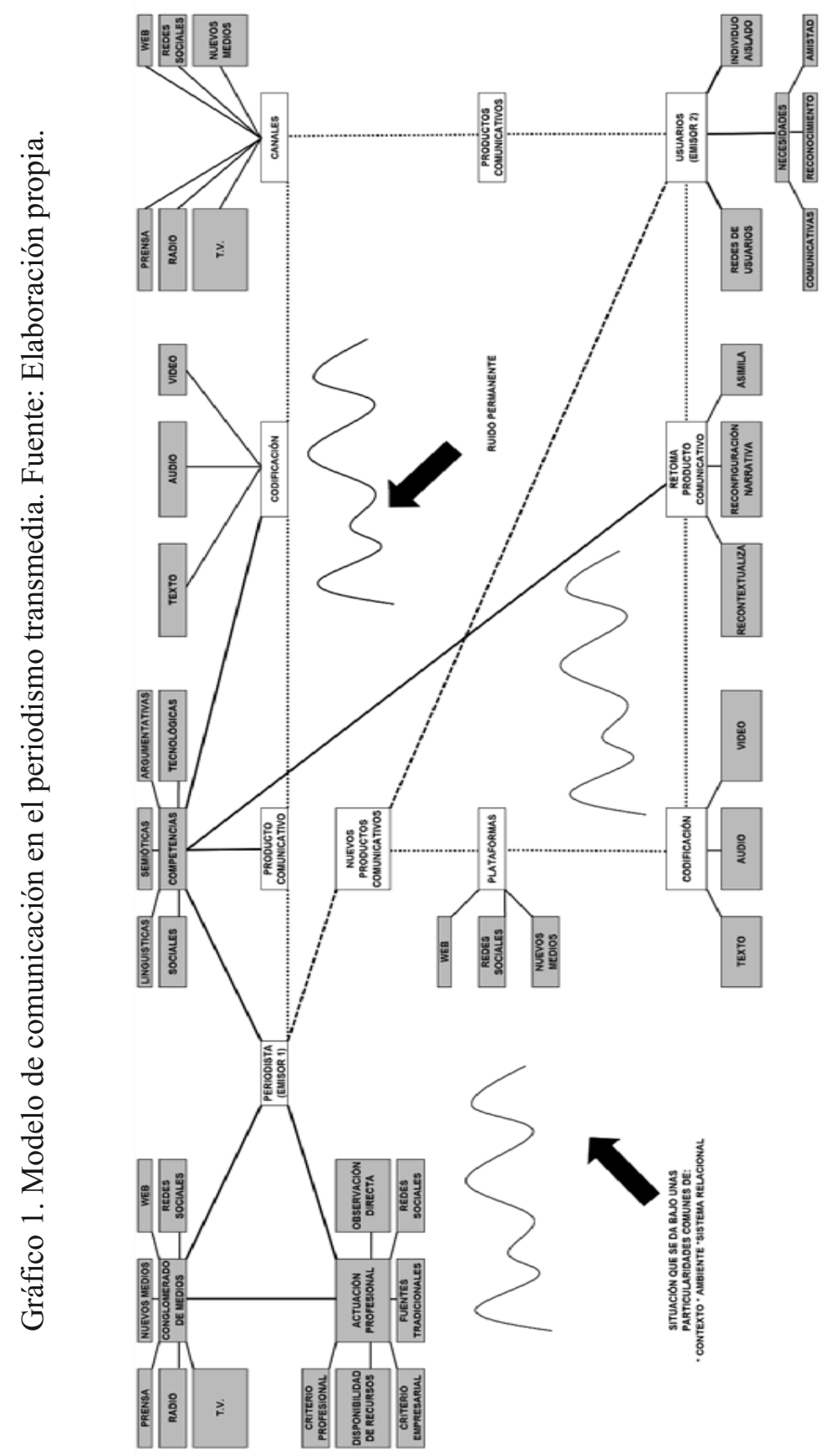

